\title{
Quantitative genetics of mating system divergence in the yellow monkeyflower species complex
}

\author{
CHARLES B. FENSTER* \& KERMIT RITLAND \\ Department of Botany, University of Toronto, Toronto, Canada M5S $3 B 2$
}

\begin{abstract}
To study the genetic basis of phenotypic changes in floral characters associated with mating system divergence in the yellow monkeyflowers (Mimulus, section Simiolus), all pairwise crosses were conducted between four taxa, of which two were independently evolved inbreeders. The effective number of genetic factors differentiating taxa for each of six characters was estimated from backcross and $\mathrm{F}_{2}$ segregation variances, using a model that incorporates dominance. The number of factors, averaged over taxa pairs, ranged from 5.3 (for stigma-anther separation) to 12.8 (for pistil length). Dominance was slight to moderate for most characters, with a slight bias for inbreeding characteristics to be dominant over outbreeding traits. $F_{2}$ segregation patterns indicate strong genetic correlations among floral size characters but variable correlation of these characters with flowering time and little correlation with stigma-anther separation. Crosses between the two selfing and two outcrossing taxa did not lead to the recovery of extreme transgressive segregants in the $F_{2}$. These results suggest that either homologous loci are involved in repeated shifts to selfing or that the likelihood of appearance of novel recombinations is limited by the large number of loci, each with small effect. The implications of these results are discussed in the context of recent models of mating system evolution.
\end{abstract}

Keywords: gene number, mating system, Mimulus, quantitative genetics.

\section{Introduction}

Predominant self-fertilization is a common and widespread condition in angiosperms, especially among annual herbs (Stebbins, 1950; Grant, 1981). The shift from outcrossing to selfing frequently involves a suite of features (Ornduff, 1969), including reduced size of attractive structures such as the corolla and a reduction in the spatial and temporal separation of anthers and stigmas within the flower. Selfing has evolved repeatedly at both the within-genus (Arenaria, Wyatt, 1988; Leavenworthia, Rollins, 1963; Lloyd, 1965; Solbrig \& Rollins, 1977) and within-species levels (Eichhornia paniculata, Husband \& Barrett, 1993; Fenster \& Barrett, 1994), with similar but non-homologous suites of characters appearing in each taxon.

The genetic basis underlying these changes of morphology associated with mating system evolution has received little investigation. These few studies, based on genetic analysis of segregation in crosses

*Correspondence: Department of Botany, University of Maryland, College Park, MD 20742-5815, U.S.A. between divergent populations within species or between related species, have shown that many genes are responsible (Turnera, Shore \& Barrett, 1990; Clarkia, Holtsford \& Ellstrand, 1992; Mimulus, Macnair \& Cumbes, 1989). In accord, mating system variation within populations is usually found to be polygenic (Breese, 1959; Shore \& Barrett, 1990; Holtsford \& Ellstrand, 1992; Carr \& Fenster, 1994), but occasionally mating system variation is associated with the segregation of major genes (Senecio, Marshall \& Abbott, 1982, 1984; Ipomea, Clegg \& Epperson, 1988).

Recent models have demonstrated that the evolutionary fate of genes for selfing depends on their level of dominance and the number of loci. Mixed-mating systems are likely to be derived from the fixation of additive or dominant genes, as opposed to genes with recessive effects, as recessive inheritance shifts equilibria towards higher selfing (Latta \& Ritland, 1993, 1994). Evolution towards complete selfing is likely with few loci because associations easily develop between loci affecting inbreeding depression and loci controlling selfing (Holsinger, 1988, 1991; Uyenoyama \& Waller, 
1991a, b, c). In contrast, polygenic control of the mating system favours a partial selfing equilibrium (Charlesworth et al., 1990; Latta \& Ritland, 1993).

Section Simiolus of Mimulus (Scrophulariaceae) consists of both predominantly selfing and predominantly outcrossing species (Ritland \& Ritland, 1989) whose specific status remains uncertain (see below). Many species are cross-compatible (Vickery, 1978), allowing for the formal genetic analysis of trait differentiation. Here, we report on the genetic basis of mating system differences between four closely related Mimulus species. Two of the species are selfers. In genera that have undergone repeated evolution of selfing, the independent evolutions of different selfing species act as 'replicates' of the evolutionary process. Comparisons of outcrossing-selfing pairs within the genus are less influenced by confounding differences of life history than are comparisons of outcrossing-selfing pairs among genera or plant families.

In this study, we performed all pairwise hybridizations between the four taxa and analysed segregation patterns in backcross and $F_{2}$ generations for gene number and levels of dominance at loci differentiating these taxa. In this process, we incorporate dominance into the estimators of gene number using a model following Serebrovsky (1928, cited in Wright, 1968). The major questions we then address are as follows. Firstly, are phenotypic differences among taxa for the mating system governed by many or few loci? Secondly, are alleles at these loci recessive in the selfing taxa? Thirdly, do changes in position of stigmas and anthers result in pleiotropic changes in other floral characters? Fourthly, are the same processes evident along independent phylogenetic lineages? Elsewhere, we report on the role of natural selection in mating system evolution (Fenster \& Ritland, 1994) and estimate genetic variation within populations for traits associated with the mating system (Carr \& Fenster, 1994).

\section{Materials and methods}

\section{Study species}

Populations of section Simiolus species occur in stream edges and wet meadows. Mimulus guttatuis DC is polytypic and has an extensive distribution in western $\mathrm{N}$. America whereas $M$. micranthus Heller and M. laciniatus Gray are monotypic and endemic to the Coast Range foothills and to the Sierra foothills of California, respectively (Grant, 1924). Mimulus nasutus Greene is intermediate in flower size and occurs in serpentine soils of northeastern California. Taxa are intercrossable (Vickery, 1978) and all have a haploid chromosome number of $n=14$ (Campbell, 1950). Mimulus guttatus is facultatively perennial whereas the other taxa are annual.

Because of the polytypic nature of $M$. guttatus, the taxonomy of section Simiolus has undergone several revisions. Mimulus micranthus and $M$. nasutus have been classified as subspecies of $M$. guttatus by some (e.g. Campbell, 1950) but as distinct species by others (e.g. Grant, 1924). The precise identity of M. nasutus is also in dispute (F. Ganders, personal communication). In keeping with some previous taxonomic treatments and with Ritland \& Ritland (1989), as well for notational brevity, we refer to each of these entities as distinct 'taxa', which implies no specific status to any.

The larger-flowered $M$. guttatus and $M$. nasutus are herkogamous and largely outcrossing $(t=0.6-0.9)$ compared with the smaller-flowered and predominantly selfing $M$. micranthus $(t=0.1-0.2)$ and $M$. laciniatus ( $t=0.2-0.4$ ) (Ritland \& Ritland, 1989). Selfing taxa show reduced allocation to a number of traits that contribute to male function including corolla size and pollen number (Ritland \& Ritland, 1989). Stigma-anther separation is correlated between populations to levels of outcrossing and autogamy (Dole, 1992) and within populations to levels of autogamy (Carr \& Fenster, 1994). Patterns of isozyme and cpDNA variation support the hypothesis that $M$. micranthus and $M$. laciniatus are independently derived from M. guttatus (Ritland \& Ritland, 1989; Fenster \& Ritland, 1992, 1994).

One population from each taxon was chosen for study and collected for seed: (1) a perennial, very largeflowered population of $M$. guttatus near the tip of $\mathrm{Pt}$ Reyes, Marin Co., (2) an annual, smaller-flowered population of $M$. nasutus individuals along Hwy 20 at Lake Co./Calousa Co. line, (3) a population of $M$. micranthus $10 \mathrm{~km}$ west of Bartlett Springs, Lake Co., and (4) a population of $M$. laciniatus $8 \mathrm{~km}$ west of Hetch-Hetchy dam, Tuloumne Co.

\section{Crosses among taxa}

All 12 pairwise reciprocal crosses among the four taxa were conducted. Authenticity of $F_{1}$ hybrids was verified by heterozygotes at isozyme loci fixed for alternative alleles in the parents. $F_{2}$ progeny were produced by intercrossing $F_{1}$ individuals. Backcrosses were performed in both directions $\left(\mathrm{BC}_{1}\right.$ and $\left.\mathrm{BC}_{2}\right)$, except that due to difficulties in performing the crosses, backcrosses were not performed using the two selfing taxa. Mimulus guttatus and $M$. nasutus parental stocks were maintained by random crossing of individuals within each species and $M$. micranthus and $M$. laciniatus parental stocks were maintained by collecting selfed seed. 
For each pair of taxa, parental, $F_{1}, B C$ and $F_{2}$ generations were grown simultaneously. The crosses $M$. guttatus $\times M$. micranthus and $M$. nasutus $\times M$. micranthus were grown in early 1989 and the crosses $M$. guttatus $\times M$. laciniatus and $M$. guttatus $\times M$. nasutus grown in mid- 1989 , both in $5 \mathrm{~cm}$ pots, at $18^{\circ} \mathrm{C} / 14^{\circ} \mathrm{C}$ day/night with $18 \mathrm{~h}$ days in a growth chamber at the University of Toronto. The crosses $M$. nasutus $\times M$. laciniatus and $M$. micranthus $\times M$. laciniatus were grown in the glasshouse at College Park, MD, in early 1990 under $18 \mathrm{~h}$ days in $5 \mathrm{~cm}$ pots but with slightly warmer temperatures. Sample sizes for all crosses are indicated in Table 1.

The following characters were measured on individuals in all generations: (1) day to first flower, (2) widest corolla width, (3) average stamen height (averaged over low and high anthers), (4) pistil length, (5) stigma-anther separation (pistil length minus high

Table 1 Generation means for each character

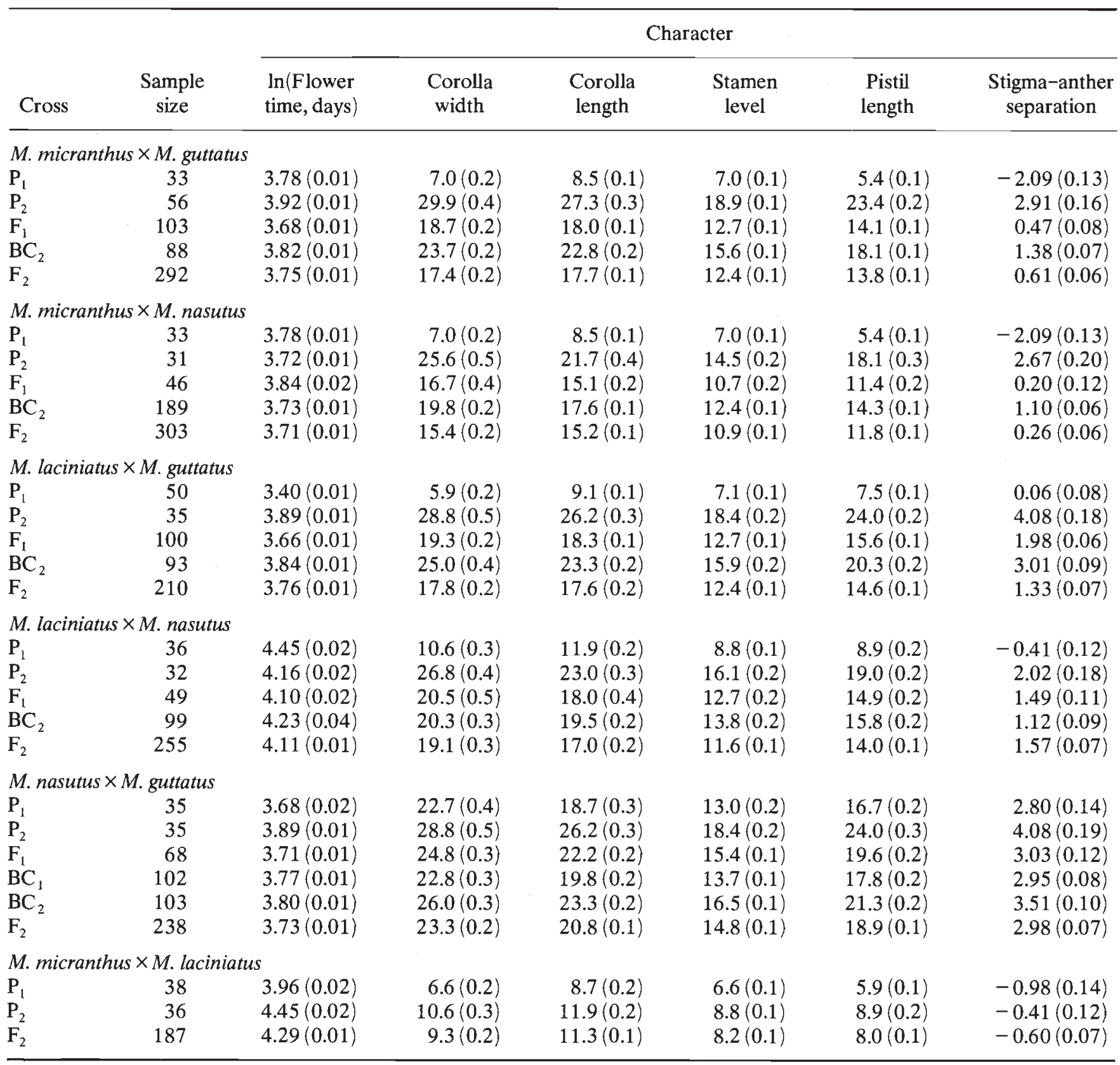

Values in parentheses are SE.

The first parent listed is the smaller-flowered of the two.

All measurements (except flower time) are in $\mathrm{mm}$. 
anther height), and (6) corolla tube length. Measurements were made using digital calipers to within $0.1 \mathrm{~mm}$ on the first opened flower of each plant. These characters all correlate with mating system evolution in Mimulus (Ritland \& Ritland, 1989; Dole, 1992; Carr \& Fenster, 1994).

Characters were left untransformed except for date of first flower. From the means and variances of parental and segregating generations, dominance and gene number were estimated with the formulae derived below. Genetic correlations (equivalently, the proportion of genetic factors in common between a pair of traits) were estimated as the segregation covariance in the $F_{2}$ (Humphreys \& Nicholls, 1984), divided by the geometric mean of the segregational variance of the two traits. The bootstrap procedure (see below) was used to calculate standard errors of estimates.

\section{Estimation of gene number with dominance of gene effects}

The well-known procedure of Wright (1968) and Lande (1981) estimates the minimum number of factors (gene loci) differentiating the two taxa as:

$N_{\mathrm{E}}=\frac{\left(U_{\mathrm{P} 1}-U_{\mathrm{P} 2}\right)^{2}-C}{8 S}$,

where $S$ is an estimate of the 'segregational variance' (increased phenotypic variance due to segregating alleles in the $\mathrm{F}_{2}$ ), the $U$ s are estimated means in the two parental taxa and $C$ is a correction factor equal to the statistical error variance of $U_{\mathrm{P} 1}-U_{\mathrm{P} 2}$ (Cockerham, 1986).

This estimator has a number of assumptions and potential biases. These include the assumptions of additivity of gene effects within and among loci, no linkage and equality of effects among loci (Wright, 1968). Non-additive gene effects among loci may either increase or decrease the estimate of gene numbers (Mather \& Jinks, 1982) but are probably small compared with the effects of linkage, which can cause a serious underestimate of the number of gene loci controlling a trait (Zeng et al., 1990). Variation of allelic effects decreases the estimate of the number of genetic factors (Zeng et al., 1990).

An assumption we will relax in this paper is that of no dominance, e.g. additivity of factors within loci. Classically, when factors appear to deviate from additivity as revealed by the means of $F_{1}$ and segregating generations, the appropriate data transformations are applied to yield additive means. However, it is often difficult to be sure that the correct transformation has been found as there are only three or four points (parental, $F_{1}$ and $F_{2}$ means) to gauge the fit of the transformation. A model for the estimation of gene number with dominance was first proposed by Serebrovsky (1928, cited in Wright, 1968), who considered the case of complete dominance. Wright (1968, pp. 383-384) later extended it to arbitrary dominance and gave a formula for estimating dominance using the parental and $F_{1}$ means. In this section we briefly describe a reparameterized version of this estimator incorporating estimates of dominance based on the segregating generations (as opposed to the $F_{1}$ ). These procedures assume uniform dominance among loci.

We first consider estimation of gene number in a segregating $\mathrm{F}_{2}$. Let two diploid taxa be fixed for alternative alleles $A_{1}$ and $A_{2}$ at each of $n$ loci controlling a character. A given locus causes a deviation from the mean phenotype of $-2 a, 2 d$, and $2 a$ for genotypes $A_{1} A_{1}, A_{1} A_{2}$ and $A_{2} A_{2}$, respectively. If $d=0$, this model becomes that of additive effects only, and if $d=-a$ or $d=a$, it portrays complete dominance. Assuming that alleles conferring an increase of the character occur in the same taxon, the means of the $P_{1}$, $\mathrm{F}_{1}$ and $\mathrm{P}_{2}$ are $u-2 a n, u+2 d n$ and $u+2 a n$, respectively. The expected segregational variance in the $F_{2}$ is $s=\left(2+d^{2}\right)\left(u_{2}-u_{1}\right)^{2} /(16 n)$, so that the estimator for gene number, obtained by solving for $n$, is:

$N_{\mathrm{E}(\mathrm{d})}=\frac{\left(2+(D / A)^{2}\right)\left(U_{\mathrm{P} 1}-U_{\mathrm{P} 2}\right)^{2}-C}{16 S}$,

where $U_{\mathrm{P} 1}$ and $U_{\mathrm{P} 2}$ are the parental means and $D / A$, the ratio of dominance to additive effects, is estimated as:

$(D / A)=\frac{2\left(U_{\mathrm{F} 2}-E_{\mathrm{F} 2}\right)}{\left(U_{\mathrm{P} 1}-U_{\mathrm{P} 2}\right)}$.

In these expressions, estimated quantities are denoted by capital letters and their true values by lower case. Also, $C$ is a correction factor equal to the statistical variance of $(2+(D / A))\left(U_{\mathrm{P} 1}-U_{\mathrm{P} 2}\right)$ and $E_{\mathrm{F} 2}=\left(U_{\mathrm{P} 1}+U_{\mathrm{P} 2}\right) / 2$ is the average of the two parental means or that expected in the absence of dominance.

In the above estimator, the ratio of dominance to additive effects is sufficient to estimate gene number (this ratio equals -1 or +1 for complete dominance). The use of $U_{\mathrm{F} 2}$ to estimate $d / a$ is somewhat arbitrary, as the mean of the $F_{1}$ might alternatively be used. However, as the degree of effective dominance can change among segregating generations due to epistasis, it is best to base the estimate of $d / a$ upon the current generation of study.

We next consider a segregating backcross taxon. This cross also yields information about dominance 
and gene number, but less efficiently. In a backcross to the first parent, the expected segregational variance is $s_{1}=\left(1+d^{2}\right)\left(u_{2}-u_{1}\right)^{2} /(16 n)$, while a backcross to the second parent has expected segregation variance $s_{2}=\left(1-d^{2}\right)\left(u_{2}-u_{1}\right)^{2} /(16 n)$. In a backcross to the first parent, let $E_{\mathrm{B} 1}=(3 / 4) U_{\mathrm{P} 1}+(1 / 4) U_{\mathrm{P} 2}$. The estimators are now:

$N_{\mathrm{E}(\mathrm{d})}=\frac{\left(1+(D / A)^{2}\right)\left(U_{\mathrm{P} 1}-U_{\mathrm{P} 2}\right)^{2}-C}{16 S}$.

$(D / A)=\frac{4\left(U_{\mathrm{B} 1}-E_{\mathrm{B} 1}\right)}{\left(U_{\mathrm{P} 1}-U_{\mathrm{P} 2}\right)}$.

The estimators for backcrosses to the second parent are the same except that B1 is replaced by B2 and P1 and $\mathrm{P} 2$ are interchanged, resulting in a degree of the sign of $\mathrm{D}$.

\section{Estimation of segregational variances via regression}

To find the segregational variance, the environmental variance in the segregating generation must be determined. Segregation variances are normally found by subtraction of the $F_{1}$ variance (purely environmental) from the variance of the segregating generation (cf. Lande, 1981). To average biases due to dependence of environmental variance on heterozygosity, Wright (1968) suggests using as the estimator of environmental variance the quantity $(1 / 4) V_{\mathrm{P} 1}+(1 / 2) V_{\mathrm{F} 1}+(1 / 4) V_{\mathrm{P} 2}$. To remove biases due to dependencies of variances on the means, one avenue is again to find an appropriate transformation (Wright, 1968).

If transformations cannot be found or are deemed unsuitable, another method is to use linear regression to estimate environmental variances in the $F_{2}$ and backcross generations. We adopted this procedure as follows. Firstly, the means for the $P_{1}, F_{1}$ and $P_{2}$ data were calculated. The data were then pooled and the squared deviations of individual observations from their means $(y$-axis $)$ were regressed on their means $\left(\mathrm{P}_{1}\right.$, $\mathrm{F}_{1}$ and $\mathrm{P}_{2}$, respectively, plotted on the $x$-axis). The fitted regression was then used to predict expected environmental variance at the observed $\mathrm{F}_{2}$ and $\mathrm{BC}$ mean values. Even if there is no dependence of variance on the mean, this procedure is most efficient at extracting information about variance but assumes linearity of dependence of the variance on the mean.

\section{Determination of statistical error}

Formulae for the variances of estimates derived by Taylor series approximations, such as those given for gene number by Lande (1981) and for genetic corre- lations by Falconer (1981), substantially underestimate the actual variance (Zeng et al., 1990). Error terms are neglected and, in addition, the skewness of the error distribution is approximated as symmetrical. To include these additional features of error, we adopted the bootstrap method (Efron \& Gong, 1983) to estimate error. In this procedure, individuals are sampled with replacement to form replicate data sets and the distribution of estimates among replicates approximates the true error distribution. In our study, we based 95 per cent confidence intervals upon the 2.5 and 97.5 percentiles of the distribution of 1000 bootstrap estimates.

\section{Results}

Parental, $F_{1}, F_{2}$ and backcross means for each character and each cross are presented in Table 1. The inbreeders, $M$. micranthus and $M$. laciniatus, generally had floral characters one-quarter to one-third the size of those of outbreeders. Between the inbreeders, $M$. micranthus exhibited significantly more extreme inbreeding features. Stamen and pistil lengths were correspondingly shorter and stigma-anther separation was negative in these inbreeders. Between the two outbreeders, $M$. guttatus exhibited more extreme outbreeding features than $M$. nasutus. However, time to flowering showed no relationship with degree of inbreeding.

Estimates of the dominance ratio, based on eqns 3 and 5, are given in Table 2. Except for days to flower, dominance effects were small and often less than 20 per cent of additive effects. Days to first flower demonstrated marked overdominance towards earlier flowering in the $F_{1}$. Among crosses, the highest level of dominance was observed between the two predominant outbreeders $M$. nasutus $\times M$. guttatus, with the smaller-flowered $M$. nasutus showing dominance. Between the two inbreeders, the larger-flowered $M$. laciniatus showed dominance over the smallerflowered $M$. micranthus. In the crosses $M$. laciniatus $\times M$. guttatus and $M$. laciniatus $\times M$. nasutus, the direction of dominance changed among generations. There are no general trends in the direction of dominance based on the $\mathrm{F}_{1}$. However, traits associated with smaller flower size demonstrate partial dominance over larger flower size in the $\mathrm{BC}$ and $\mathrm{F}_{2}$ generations. Among floral characters, stigma-anther separation showed the largest deviations from additivity.

A typical distribution of the characters across generations is presented for corolla width for the cross $M$. micranthus $\times M$. guttatus (Fig. 1). The observation of variation in the parental and $F_{1}$ generations and little overlap of the $F_{2}$ with either parental, suggests that the segregation of many loci of small effects is responsible 
Table 2 Estimates of degree of dominance in $F_{1}$, backcross and $F_{2}$ generations

\begin{tabular}{|c|c|c|c|c|c|c|}
\hline & $\begin{array}{l}\ln (\text { Flower } \\
\text { time, days })\end{array}$ & $\begin{array}{l}\text { Corolla } \\
\text { width }\end{array}$ & $\begin{array}{l}\text { Corolla } \\
\text { length }\end{array}$ & $\begin{array}{c}\text { Stamen } \\
\text { level }\end{array}$ & $\begin{array}{l}\text { Pistil } \\
\text { length }\end{array}$ & $\begin{array}{l}\text { Stigma-anther } \\
\text { separation }\end{array}$ \\
\hline \multicolumn{7}{|c|}{$M$. micranthus $\times M$. guttatus } \\
\hline$F_{1}$ & $-2.41(0.33)$ & $0.02(0.03)$ & $0.01(0.02)$ & $-0.04(0.03)$ & $-0.04(0.02)$ & $0.02(0.05)$ \\
\hline $\mathrm{BC}_{2}$ & $-1.79(0.35)$ & $-0.08(0.06)$ & $0.04(0.05)$ & $-0.11(0.05)$ & $-0.18(0.04)$ & $-0.22(0.11)$ \\
\hline $\mathrm{F}_{2}$ & $-1.42(0.21)$ & $-0.09(0.02)$ & $-0.03(0.02)$ & $-0.09(0.02)$ & $-0.07(0.02)$ & $0.08(0.05)$ \\
\hline $\mathrm{BC}_{2}$ & $0.33(1.13)$ & $-0.24(0.08)$ & $-0.25(0.08)$ & $-0.15(0.09)$ & $-0.21(0.06)$ & $-0.32(0.14)$ \\
\hline $\mathrm{F}_{2}$ & $1.13(0.78)$ & $-0.10(0.03)$ & $0.01(0.03)$ & $0.04(0.04)$ & $0.01(0.02)$ & $-0.01(0.06)$ \\
\hline \multicolumn{7}{|c|}{ M. laciniatus $\times M$. guttatus } \\
\hline$F_{1}$ & $0.10(0.07)$ & $0.17(0.03)$ & $0.07(0.02)$ & $-0.01(0.02)$ & $-0.02(0.02)$ & $-0.04(0.05)$ \\
\hline $\mathrm{BC}_{2}$ & $0.10(0.58)$ & $-0.59(0.10)$ & $-0.26(0.11)$ & $-0.28(0.12)$ & $-0.28(0.08)$ & $-0.48(0.26)$ \\
\hline $\mathrm{F}_{2}$ & $1.37(0.19)$ & $0.06(0.04)$ & $-0.09(0.04)$ & $-0.22(0.04)$ & $0.01(0.04)$ & $0.63(0.13)$ \\
\hline \multicolumn{7}{|c|}{$M$. nasutus $\times M$. guttatus } \\
\hline$F_{1}$ & $-0.69(0.18)$ & $-0.31(0.13)$ & $-0.06(0.06)$ & $-0.12(0.06)$ & $-0.19(0.06)$ & $-0.64(0.29)$ \\
\hline $\mathrm{BC}_{1}$ & $-0.76(0.28)$ & $-0.89(0.25)$ & $-0.54(0.16)$ & $-0.44(0.14)$ & $-0.47(0.14)$ & $-0.77(0.52)$ \\
\hline $\mathrm{BC}_{2}$ & $0.80(0.34)$ & $-0.95(0.30)$ & $-0.41(0.15)$ & $-0.47(0.16)$ & $-0.43(0.13)$ & $-0.51(0.61)$ \\
\hline & $-0.48(0.14)$ & $-0.80(0.12)$ & $-0.45(0.05)$ & $-0.34(0.06)$ & $-0.41(0.05)$ & $-0.72(0.26)$ \\
\hline \multicolumn{7}{|c|}{ M. micranthus $\times M$. laciniatus } \\
\hline $\mathrm{F}_{2}$ & $0.32(0.07)$ & $0.34(0.15)$ & $0.62(0.13)$ & $0.44(0.12)$ & $0.39(0.10)$ & $0.34(0.44)$ \\
\hline
\end{tabular}

Values in parentheses are SE.

The first parent listed for a cross is the smaller-flowered parent.

for increased variation in the $\mathrm{F}_{2}$. This is supported by our estimates of the number of factors differentiating pairs of taxa, based on eqns 2 and 4 . The averages over all crosses ranged from 5 to 12 factors (Table 3 ). The lowest number of genes was exhibited by stigma-anther separation, while pistil length showed the highest numbers of factors. Because days to first flower showed overdominance, estimates for this character were very low and should be regarded as artifacts of overdominance.

Individuals in the $F_{2}$ generation more extreme than either parent were only observed for the trait corolla width for the crosses $M$. micranthus $\times M$. laciniatus (Fig. 2a) and M. nasutus $\times M$. guttatus (Fig. 2b). However, there were no significant departures of the frequencies in the tails of the $F_{2}$ distributions from those expected, based on the means and standard deviations of the parental generations.

The 95 per cent confidence intervals given in Table 3 , obtained by the bootstrap procedure, show substantial errors of estimates. Figure 3 illustrates how the error is markedly skewed in the positive direction, in the case of corolla width in the cross $M$. micranthus $\times M$. guttatus based on segregation observed in the $F_{2}$ generation (eqn 2). This skewness lengthens the upward bound considerably above that expected from standard errors.

Because of the large errors in the positive direction, few estimates of gene number were significantly less than 10 and many were extremely large. Significantly fewer than 10 loci controlled differences between $M$. laciniatus and $M$. guttatus for two characters (stamen level, stigma-anther separation) and between $M$. laciniatus and $M$. nasutus for three characters (corolla width, stamen level, stigma-anther separation). Because of the skewed error, the lower bounds for estimates are more informative. Lower bounds ranged from zero (indicating no segregational variance) to 10 (shown by pistil length).

Table 4 gives the estimates of genetic correlations between characters shown in the $F_{2}$ generation. All size characters (corolla width, corolla length, anther height, pistil length) have consistently high positive genetic correlations with each other. In contrast, date of first 

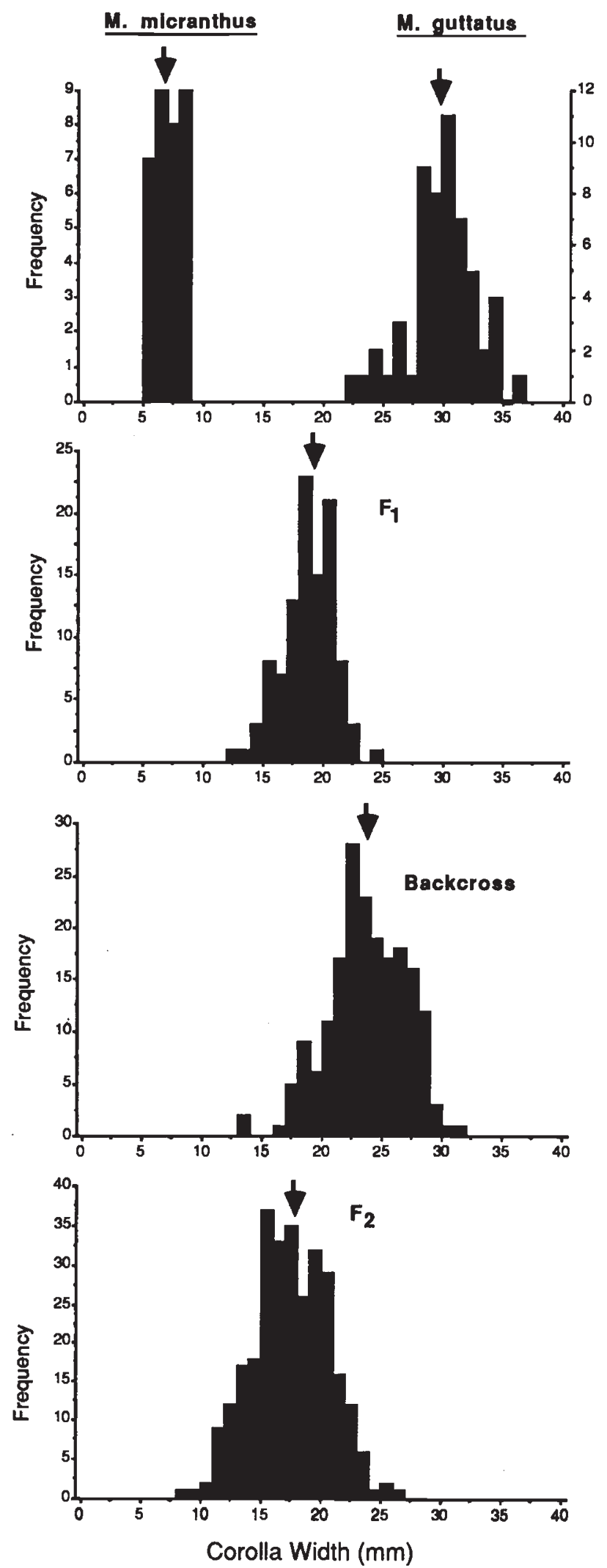

Fig. 1 Distribution of corolla widths for parental, $\mathrm{F}_{1}, \mathrm{BC}_{2}$ and $\mathrm{F}_{2}$ generations in the cross $M$. micranthus $\times M$. guttatus (arrows denote means). flower showed a variable correlation with other characters among pairs of taxa. Crosses with $M$. micranthus suggest a weak relationship between date of first flower and flower size, while crosses involving either $M$. guttatus or $M$. nasutus with $M$. laciniatus suggest earlier flowering plants have reduced flower size. Date of first flower was not consistently correlated with stigma-anther separation.

Stigma-anther separation was weakly and erratically correlated with corolla width, corolla length and anther height but showed a consistent positive correlation with pistil length (Table 4). Partial correlation analysis of the segregation covariance reveals a much stronger negative association between stigma-anther separation and anther height (Table 5).

No maternal effects were observed in crosses between $M$. guttatus and $M$. laciniatus or $M$. nasutus with either $M$. micranthus or M. laciniatus (results not shown). In the cross $M$. micranthus $\times M$. guttatus, all traits except stigma-anther separation showed small maternal effects, about 5-20 per cent of their maximum values. The effects largely disappeared in the $F_{2}$ for all traits except corolla width and stigma-anther separation. They are expected to increase estimates of the $F_{1}$ and $F_{2}$ variances and hence to lower the estimates of the number of factors differentiating the taxa.

\section{Discussion}

\section{Gene number}

In general, we found that many genes are responsible for the evolution of inbreeding in Mimulus, section Simiolus. Estimates of the number of genetic factors were close to the number of chromosomal segments segregating (14 for Mimulus, Vickery, 1978). Macnair \& Cumbes (1989) also estimated gene number between another small-flowered selfer, $M$. cupriphilus (presumably independently derived) and the largerflowered $M$. guttatus. Their results were similar to our own, i.e. many genes appear to be responsible for the differentiation of floral characters among Mimulus taxa. The exception observed in the cross of $M$. laciniatus $\times M$. nasutus may be associated with a greater role of epistasis differentiating these taxa (see below). In addition, the low estimates of number of loci differentiating $M$. macranthus from $M$. laciniatus are likely to be biased downward by transgressive segregation. Although the two species differ significantly for the traits, the gene counting procedure employed here assumes all loci are fixed in the same direction and is best used when parental strains differ greatly (Wright, 1968). Note that our estimates of gene number were 
Table 3 Estimates of the minimum number of genetic factors separating taxa for floral characters, obtained with the procedure that allows for uniform dominance

\begin{tabular}{|c|c|c|c|c|c|c|}
\hline & $\begin{array}{l}\text { In (Flower } \\
\text { time, days })\end{array}$ & $\begin{array}{l}\text { Corolla } \\
\text { width }\end{array}$ & $\begin{array}{l}\text { Corolla } \\
\text { length }\end{array}$ & $\begin{array}{c}\text { Stamen } \\
\text { level }\end{array}$ & $\begin{array}{l}\text { Pistil } \\
\text { length }\end{array}$ & $\begin{array}{l}\text { Stigma-anther } \\
\text { separation }\end{array}$ \\
\hline $\mathrm{BC}_{2}$ & $14.5(0.0-116)$ & $8.9(5.0-30.2)$ & $8.4(4.9-20.6)$ & $6.5(4.2-11.8)$ & $19.1(12.7-36.9)$ & $9.4(0.0-111)$ \\
\hline $\mathrm{F}_{2}$ & $1.1(0.5-6.3)$ & $9.4(6.9-14.4)$ & $12.1(9.1-18.6)$ & $11.6(8.4-17.6)$ & $15.0(10.0-20.4)$ & $6.1(3.6-16.0)$ \\
\hline \multicolumn{7}{|c|}{$M$. micranthus $\times M$. nasutus } \\
\hline \multicolumn{7}{|c|}{ M. laciniatus $\times M$. guttatus } \\
\hline $\mathrm{BC}_{2}$ & $5.1(0.0-44.9)$ & $7.9(4.5-18.6)$ & $13.0(7.6-41.1)$ & $5.7(3.2-13.4)$ & $9.3(5.5-21.2)$ & Undefined \\
\hline $\mathrm{F}_{2}$ & $1.3(0.9-2.4)$ & $11.8(7.9-19.3)$ & $9.8(7.3-13.9)$ & $6.8(5.4-9.1)$ & $13.2(9.9-18.5)$ & $4.1(2.7-6.8)$ \\
\hline \multicolumn{7}{|c|}{ M. laciniatus $\times M$. nasutus } \\
\hline $\mathrm{BC}_{2}$ & $0.1(0.0-1.1)$ & $0.0(0.0-5.8)$ & $0.3(0.0-2.1)$ & $0.7(0.0-5.8)$ & $0.7(0.1-2.8)$ & Undefined \\
\hline $\mathrm{F}_{2}$ & $1.3(0.6-7.3)$ & $3.7(1.3-92.3)$ & $7.8(3.5-66.4)$ & $9.9(3.8-90.8)$ & $11.3(5.2-165)$ & $2.6(0.5-50.2)$ \\
\hline \multicolumn{7}{|c|}{ M. micranthus $\times$ M. laciniatus } \\
\hline $\mathrm{F}_{2}$ & $5.1(2.3-27.4)$ & $0.7(0.4-1.7)$ & $0.8(0.4-2.4)$ & $1.0(0.5-2.4)$ & $1.4(0.9-6.9)$ & $0.2(0.1-2.4)$ \\
\hline \multicolumn{7}{|c|}{ Mean of selfers $\times$ outcrossers (first four crosses above) } \\
\hline $\mathrm{F}_{2}$ & $0.8(0.6-2.1)$ & $9.5(7.5-17.4)$ & $10.3(8.0-22.1)$ & $7.7(6.3-11.3)$ & $12.8(10.0-16.2)$ & $5.3(3.4-35.9)$ \\
\hline
\end{tabular}

Values in parentheses are $95 \%$ confidence intervals.

changed by less than five per cent when we incorporated dominance and are consistent with Wright's (1968) observation that unless dominance is strong the gene counting methods are relatively insensitive to dominance.

The isozyme and cpDNA evidence for the independent origin of $M$. laciniatus and $M$. micranthus (Ritland \& Ritland, 1989; Fenster \& Ritland, 1992, 1994) suggests that the evolution of selfing in these taxa should involve different genes. However, the lack of extreme transgressive phenotypes in the $F_{2}$ of crosses between the two inbreeding and two outbreeding taxa suggests that similar genetic and developmental mechanisms are shared by the closely related taxa. Alternatively, the lack of novel recombinants may reflect the segregation of large numbers of loci of small effect involved with the reduction of flower size. In contrast, controlled crosses among selfing variants from different parts of the range of Eichhornia paniculata in Brazil indicate that different recessive genes are responsible for changes in filament height associated with the evolution of selfing and suggest that one or a few loci may control filament length (Fenster \& Barrett, 1994).
The method we have used to estimate gene number provides a minimum estimate of the number of loci differentiating two species. A single gene (or leading factor) can be responsible for as much as $1 / \sqrt{ } n$ of the genetic variation segregating in the $\mathrm{F}_{2}$, where $n$ is the number of factors differentiating the two taxa (Wright, 1968; Lande, 1981). Major genes, if present, probably contribute proportionally less to the differences between taxa because of linkage and departures from additivity. With estimates of 5-10 linkage groups segregating alleles for stigma-anther separation in the $\mathrm{F}_{1}$ of the wide crosses of $M$. guttatus with either $M$. micranthus or $M$. laciniatus, roughly $32-45$ per cent of the $\mathrm{F}_{2}$ variance can be explained by a major gene. This corresponds to a major gene causing a decrease in stigma-anther separation of approximately 0.4-0.7 $\mathrm{mm}$.

Some studies of variation within species have found single gene mutations of large phenotypic effect (Gottlieb, 1984; Ambros, 1988; Sawhney, 1992). One cannot determine, however, if these mutations will eventually be responsible for the evolution of differences among new taxa (the 'mutational fallacy', cf. Coyne \& Lande, 1985). However, a retrospective 
study such as our own cannot reconstruct the sequence of genetic events responsible for mating system evolution. For example, we cannot ascertain whether a single major gene initiated the evolution of selfing, with the

(a)
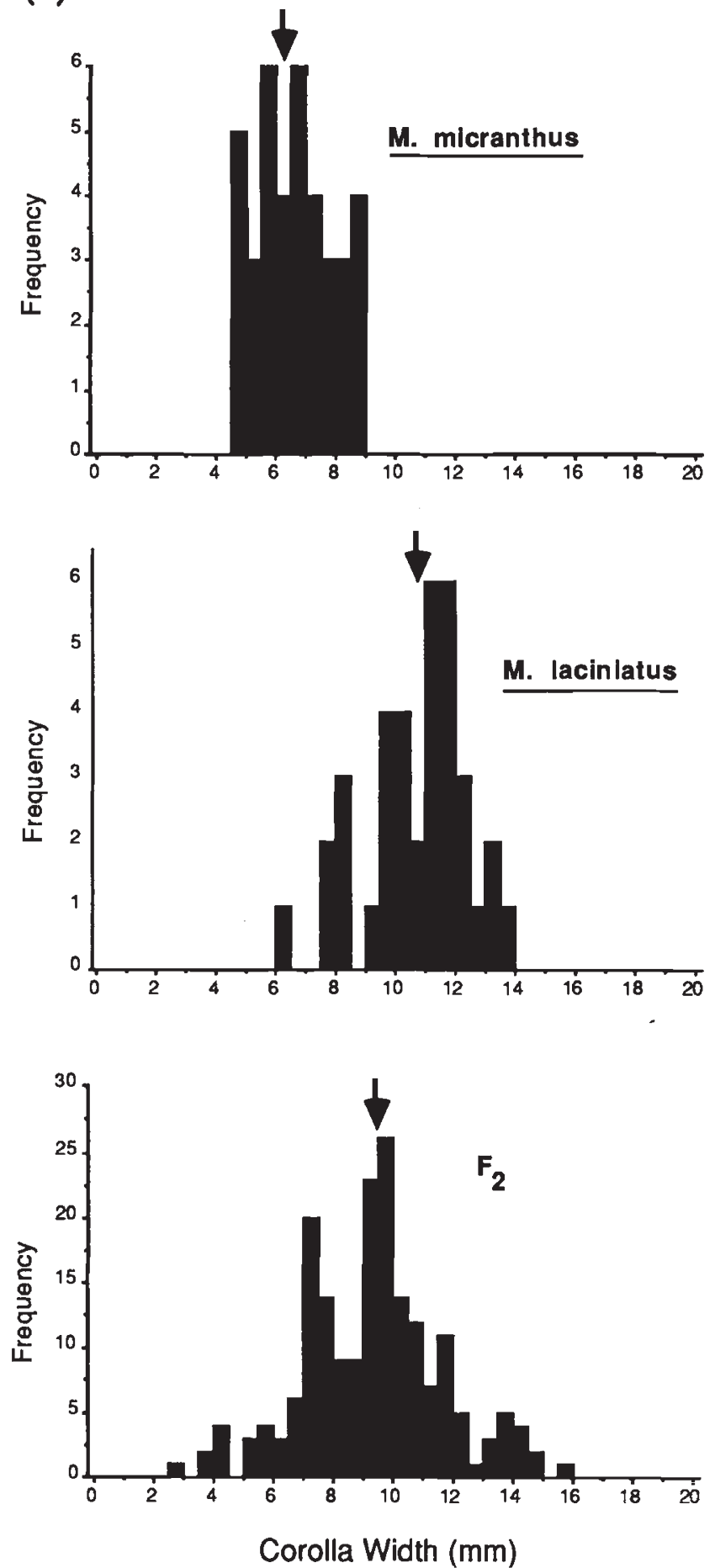

subsequent build-up of minor modifier genes, or whether polygenes were responsible from the beginning. Studies of extant genetic variation in outcrossing populations of $M$. guttatus do not provide any evidence (b)
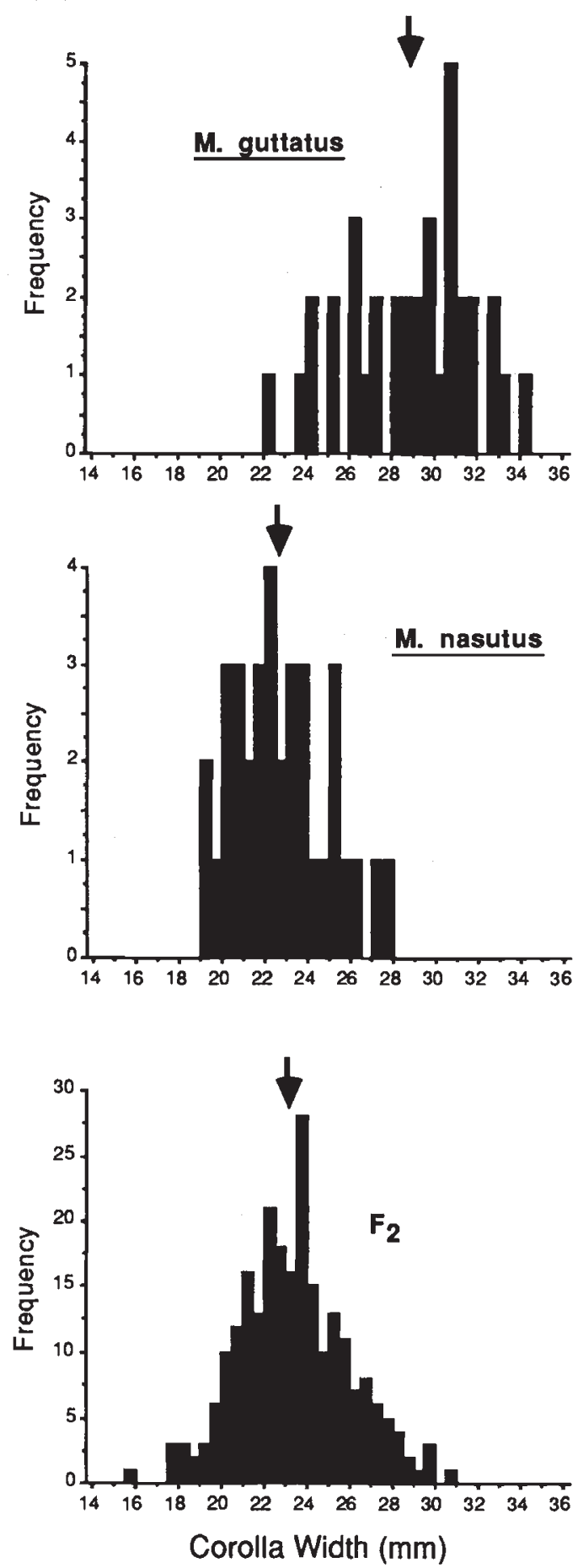

Fig. 2 Distribution of corolla widths for parental and $\mathrm{F}_{2}$ generations in the crosses: (a) M. micranthus $\times$ M. laciniatus, (b) $M$. nasutus $\times M$. guttatus (arrows denote means). The appearance of $F_{2}$ segregants that exceed the parental ranges is an artifact of the limited sample sizes of the parental generations. 


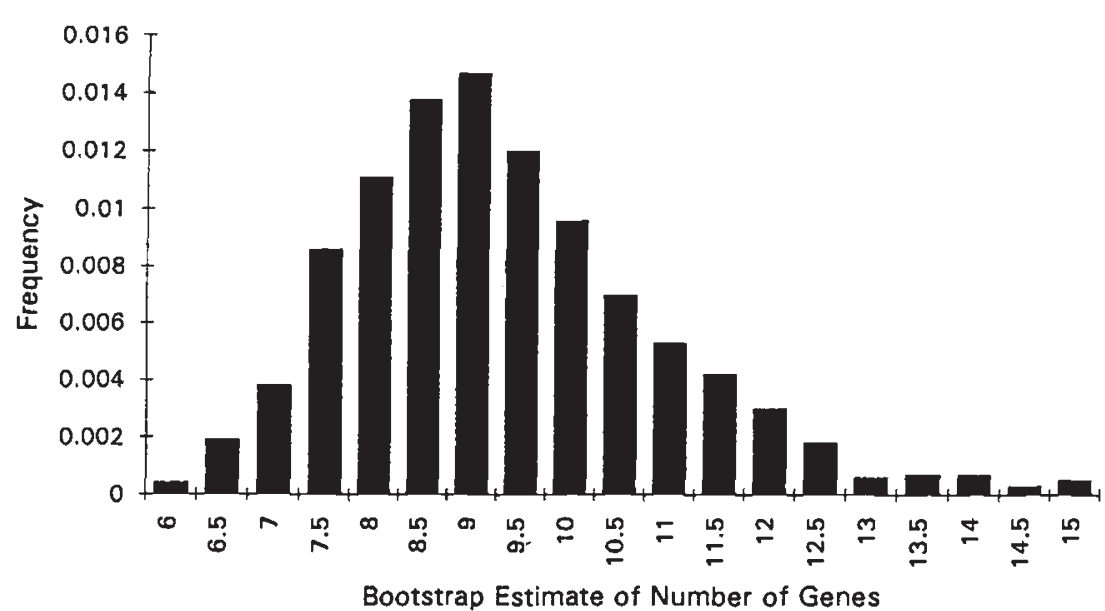

Fig. 3 Distribution of bootstrap estimates for the number of genes controlling corolla width for the cross $M$. micranthus $\times$ M. guttatus. of major gene control of any of the floral characters associated with mating system evolution (Carr \& Fenster, 1994). We suggest that molecular methods, if they can determine the ages of all alleles responsible for mating system differentiation, may offer a definitive picture of this historical process.

The magnitude of trait differences between taxa showed little relationship with the estimated number of genes causing these differences. For example, despite their sharing of a number of outcrossing features, the number of genetic factors differentiating the largerflowered $M$. guttatus and $M$. nasutus was usually large, and on average, did not differ from the number of factors differentiating inbreeders from outbreeders. In contrast, stigma-anther separation showed less differentiation between $M$. nasutus and M. laciniatus and the estimate of gene number was likewise low. Thus, differences in trait values among taxa are not associated with the number of factors differentiating them.

We have also emphasized in this paper the nature of the error distribution of gene number estimates and the utility of using the bootstrap method (Efron \& Gong, 1983 ) to estimate errors of gene number estimates, as well as genetic correlation estimates. Estimates of gene number have very uncertain upper limits due to the positive skewness of the error distribution (Fig. 3). By contrast, the lower bound is much more certain. Because most violations of the Wright estimator (variation of gene effect among loci, linkage) result in downward bias of estimates, in the light of the positive skewness of error, we conclude that the lower error bound is quite robust as a minimum estimate, while the upper error bound is neither a maximum estimate nor a very certain estimate. Indeed the standard errors based on the formula given in Lande (1981) (not shown here) generally correspond to the lower error bound and differ more from the upper bound.

\section{Gene action}

Most traits demonstrated limited dominance, especially for the crosses between selfers and outcrossers. Dominance should increase the probability and rate of evolution for selfing (Haldane, 1927), and the partial dominance towards inbreeding characters suggests that the rate of evolution of selfing from outcrossing would be accelerated. If outcrossing had evolved from selfing, the level of dominance should have no effect upon the spread of alleles increasing outcrossing and there should not be any trends in the level of dominance. Thus, our results support the scenario that selfing has evolved from outcrossing through the spread of mildly dominant mutations. The evolution of selfing from outcrossing is also supported by reduced species-wide levels of isozyme and cpDNA variation in $M$. micranthus vs. $M$. guttatus which are indicative of a progenitor-derived species pair (Fenster \& Ritland, 1992).

Different dominance relationships were quantified by Macnair and Cumbes (1989) in the cross between $M$. guttatus and the smaller-flowered $M$. cupriphilus. Generally, they observed dominance towards the $M$. guttatus phenotype for many of the same floral traits measured here. Macnair (1989) provides evidence that $M$. cupriphilus is very recently derived. The limited dominance in our crosses may reflect either the evolution of loss of dominance in less recently derived selfers or different sets of loci responsible for differentiation across taxa.

Dominance, however, is not a necessary precondition for the evolution of selfing as recessive adaptations can readily evolve in a mixed-mating system (Charlesworth, 1992). Limited dominance is often observed for many quantitative traits (Falconer, 1981) and is further suggestive that many loci of small effect are responsible 


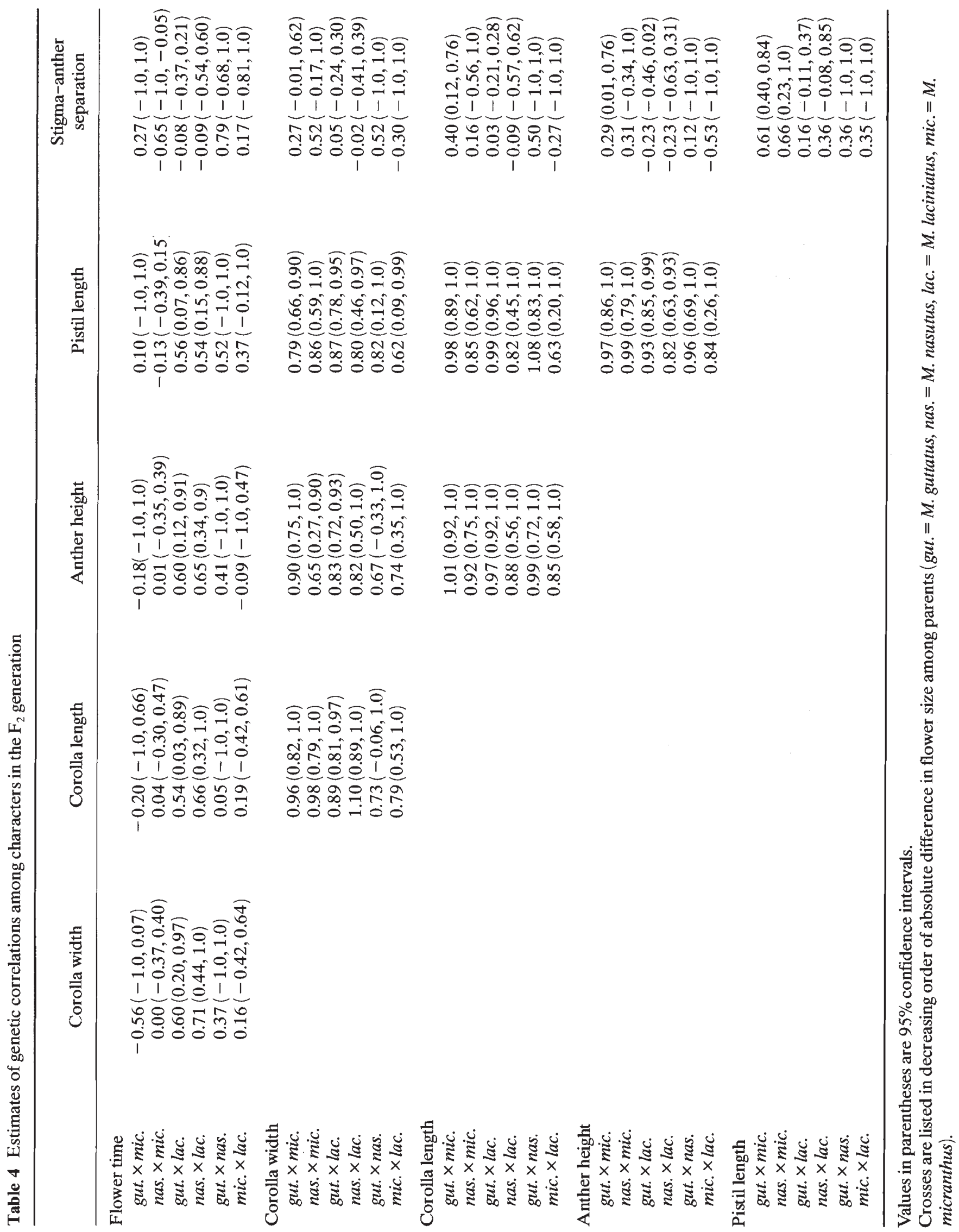


Table 5 Partial genetic correlations of stigma-anther separation with pistil length and stamen level

\begin{tabular}{lcc}
\hline \multicolumn{1}{c}{ Cross } & $\begin{array}{c}\text { Pistil } \\
\text { length }\end{array}$ & $\begin{array}{c}\text { Anther } \\
\text { height }\end{array}$ \\
\hline M. guttatus $\times$ M. micranthus & 0.72 & -0.43 \\
M. guttatus $\times$ M. laciniatus & 0.99 & -0.99 \\
M. nasutus $\times$ M. laciniatus & 0.86 & -0.79 \\
M. micranthus $\times$ M. laciniatus & 0.57 & -0.54 \\
\hline
\end{tabular}

All values are significant at $P<0.001$.

for trait differentiation (Kacser \& Burns, 1981). Furthermore, intermediate $F_{1}$ values may reflect directional selection acting on inherent variation within a population rather than the occurrence of new mutations (Charlesworth, 1992). Investigation of withinpopulation patterns of genetic variation in $M$. guttatus reveals the presence of significant amounts of additive genetic variation for floral characters associated with mating system and implies a limited contribution of dominance effects to intrapopulation levels of genetic variation (Carr \& Fenster, 1994). A very significant exception to the pattern of dominance was observed for days to first flower where overdominance was consistently observed. Indeed, characters more closely associated with fitness are expected to be more often controlled by genes with nonadditive effects (Falconer, 1981).

Changes in the direction of dominance from $F_{1}$ and $F_{2}$ to $B C_{2}$ generations is indicative of epistatic gene interaction. A joint scaling test was used to determine the relative contribution of additive and nonadditive gene action (Mather \& Jinks, 1982, analysis not shown here). Lack of backcrosses to the selfing species allowed us to test only a subset of the genetic components. Estimates of the genetic components associated with epistatic gene action were almost always much smaller than additive effects and, with few exceptions, smaller than dominance effects. The exception involved the cross of $M$. laciniatus $\times M$. nasutus. The greatest reversals of dominance effects from $F_{1}$ to $B_{2}$ were also observed in this cross. These results suggest that the lower estimates of gene number differentiating $M$. laciniatus from $M$. nasutus may in part be an artifact of increased epistasis. However, we conclude that the evolution of mating system in Mimulus is predominantly dependent on the fixation of alleles with mostly additive effects.

\section{Genetic correlations}

We found strong positive genetic correlations among characters associated with floral size in Mimulus. If the genetic correlations based on the $F_{2}$ segregation patterns reflect population patterns of covariation during the evolution of selfing, then selection on one floral character may have resulted in a correlated response in other characters. Similar genetic correlations are also observed within populations of $M$. guttatus and M. micranthus (Carr \& Fenster, 1994), supporting our inferences from this current study.

The genetic correlations between the time of first flower and other floral characters were inconsistent in sign and varied depending on the parental species. Crosses of $M$. micranthus with either $M$. guttatus or $M$. nasutus revealed that floral morphology was either negatively or weakly genetically correlated to time of first flower. Macnair \& Cumbes (1989) also observed a lack of correlation between flowering time and degree of herkogamy. In contrast, crosses of $M$. laciniatus with the two outcrossing taxa demonstrated consistent strong positive genetic correlations of time to first flower with other floral characters. Parent-offspring regressions and correlations among family means for two populations of $M$. guttatus and $M$. micranthus, respectively, also revealed that the genetic correlation of time of first flower with other floral traits varies at the population level (Carr \& Fenster, 1994). Taken together, these results suggest that mating system may or may not be a correlated response to selection for rapid development (Lloyd, 1965; Moore \& Lewis, 1965; Solbrig \& Rollins, 1977). The trajectory of trait evolution will ultimately depend on the genetic architecture particular to the evolutionary lineage.

Stigma-anther separation showed no consistent genetic correlations with the other characters. This may reflect the relatively late developmental processes responsible for positioning of stigma and anther (Lord \& Hill, 1987; Richards \& Barrett, 1992). Consequently, the loss of herkogamy may not reduce male fertility because of correlated changes in floral features associated with pollinator attraction (Epperson \& Clegg, 1987; Ritland, 1991). Closer proximity of stigma and anthers actually promoted pollen export to females in Ipomopsis aggregata (Campbell, 1989), presumably because pollen was placed on a location of the pollinator which increased its transfer efficiency. Therefore, shifts in the mating system in Mimulus, or in other groups, may not be constrained by pleiotropic action of loci associated with decreased stigma-anther separation. 


\section{Evolutionary consequences of polygenic control}

Polygenic control of mating systems has consequences for the dynamics of the evolution of selfing in Mimulus. Simulations have demonstrated that the likely outcome of major gene control is the frequent association of the mating system modifying locus with individuals with low genetic load (Holsinger, 1988; Charlesworth et al., 1990). Thus the evolution of selfing is more likely with major genes. This is a result of Fisher's (1941) observation of the 50 per cent transmission advantage of selfers over outcrossers in the absence of inbreeding depression or pollen discounting (Holsinger et al., 1984). The polygenic control of mating system in Mimulus implies that such associations are unlikely and that factors other than the 50 per cent transmission advantage are likely to be responsible for the evolution of selfing. Polygenic inheritance, intermediate heritabilities and additivity or slight dominance for selfing characters favour the maintenance of a stable mixedmating system (Latta \& Ritland, 1993, 1994). Thus the genetic architecture for mating system variation in Mimulus documented here corresponds to the observation of mixed-mating sytems in Mimulus which span the range from predominant selfing to predominant outcrossing but do not include either complete outcrossing or complete selfing (Ritland \& Ritland, 1989).

\section{Acknowledgements}

We thank P. Donnelly and B. Morton for technical assistance, J. Shore for kindly tailoring a computer program allowing us to perform joint scaling tests in the absence of one backcross generation, D. Carr, J. Dole, M. Dudash and an anonymous reviewer for helpful comments on previous versions of the manuscript, the Natural Sciences and Engineering Research Council of Canada for an operating grant to K. Ritland and set-up funds from the University of Maryland to C. Fenster.

\section{References}

AMBROS, v. 1988. Genetic basis for heterochronic variation. In: McKinney, M. L. (ed.) Heterochrony in Evolution, pp. 269-285. Plenum Press, New York.

BREESE, E. L. 1959. Selection for differing degrees of outbreeding in Nicotiana rustica. Ann. Bot., 23, 331-344.

CAMPBELL, D. R. 1989. Measurements of selection in a hermaphroditic plant: variation in male and female pollination success. Evolution, 43, 318-334.

CAMPBELl, G. R. 1950. Mimulus guttatus and related species. El Aliso, 2, 319-335.

CARR, D. E. AND FENSTER, C. B. 1994. Levels of genetic variation and covariation for Mimulus (Scrophulariaceae) floral traits. Heredity, 72, 606-618.
CHARLESWORTH, B. 1992. Evolutionary rates in partially fertilizing species. Am. Nat., 140, 126-148.

CHARLESWORTH, D., MORGAN, M. T. AND CHARLESWORTH, B. 1990. Inbreeding depression, genetic load and the evolution of outcrossing rates in a multilocus system with no linkage. Evolution, 44, 1469-1489.

CLEGG, M. T. AND EPPERSON, B. K. 1988. Natural selection of flower color polymorphisms in morning glory populations. In Gottlieb, L. D. and Jain, S. K. (eds) Plant Evolutionary Biology, pp. 255-273. Chapman and Hall, London.

CoCKerham, C. C. 1986. Modifications in estimating the number of genes for a quantitative character. Genetics, 114, 659-664.

COYNE, J. A. AND LANDE, R. 1985. The genetic basis of species differences in plants. Am. Nat., 126, 141-145.

DOLE, J. A. 1992. Reproductive assurance mechanisms in three taxa of the Mimulus guttatus complex (Scropulariaceae). Am. J. Bot., 79, 650-659.

EFRON, B. AND GONG, G. 1983. A leisurely look at the bootstrap, the jackknife and cross-validation. Am. Stat., 37, 36-48.

EPPERSON, B. K. AND CLEGG, M. T. 1987. Frequency-dependent variation for outcrossing rate among flower-color morphs of Ipomoea purpurea. Evolution, 41, 1302-1311.

FALCONER, D. S. 1981. Introduction to Quantitative Genetics, 2nd edn. Longman, London.

FENSTER, C. B. AND BARRETT, S. C. H. 1994. Inheritance of matingsystem modifier genes in Eichhornia paniculata (Pontederiaceae). Heredity, 72, 433-445.

FENSTER, C. B. AND RITLAND, K. 1992. Chloroplast DNA and isozyme diversity in two Mimulus species (Scrophulariaceae) with contrasting mating systems. Am. J. Bot., 79, 1440-1447.

FENSTER, C. B. AND RITLAND, K. 1994. Evidence for natural selection on mating system in Mimulus (Scrophulariaceae). Int. J. Pl. Sci., in press.

FISHER, R. A. 1941. Average excess and average effect of a gene substitution. Ann. Eugen., 11, 53-63.

GOTTLIEB, L. D. 1984. Genetics and morphological evolution in plants. Am. Nat., 123,681-709.

GRANT, A. L. 1924. A monograph of the genus Mimulus. Ann. Mo. Bot. Gard., 11, 99-388.

GRANT, v. 1981. Plant Speciation. Columbia University Press, New York.

HALDANE, J. B. S. 1927. A mathematical theory of natural and artificial selection. V. Selection and mutation. Proc. Camb. Phil. Soc., 23, 838-844.

HOLSINGER, K. E. 1988. Inbreeding depression doesn't matter: the genetic basis of mating system evolution. Evolution, 42, 1235-1244.

HOLSINGER, K. E. 1991. Inbreeding depression and the evolution of plant mating systems. Trends Ecol. Evol., 6, 307-308.

HOLSINGER, K. E., FELdMAN, M. W. AND Christiansen, R. B. 1984. The evolution of self-fertilization in plants. A population genetic model. Am. Nat., 124, 446-453.

HOLTSFORD, T. P. AND ELLSTRAND, N. C. 1992. Genetic and environmental variation in floral traits affecting outcrossing rate in Clarkia tembloriensis (Onagraceae). Evolution, 46, 216-225. 
HUMPHREYS, M. O. AND NiCHOLLS, M. K. 1984. Relationships between tolerance to heavy metals in Agrostis capillaris (A. tenuis Sibth.). New Phytol., 98, 177-190.

HUSBAND, B. C. AND BARRETT, S. C. H. 1993. Multiple origins of self-fertilization in tristylous Eichhornia paniculata (Pontederiaceae): inferences from style morph and isozyme variation. J. Evol. Biol., 6, 591-608.

KACSER, H. AND BURNS, J. A. 1981. The molecular basis of dominance. Genetics, 97, 639-666.

LANDE, R. 1981. The minimum number of genes contributing to quantitative variation between and within populations. Genetics, 99, 541-553.

LATTA, R. AND RITLAND, K. 1993. Models of the evolution of selfing under alternative models of inheritance. Heredity, 71, 1-10.

LATTA, R. AND RITLAND, K. 1994. The relationship between inbreeding depression and prior inbreeding among populations of four Mimulus taxa. Evolution, 48, in press.

LLOYD, D. G. 1965. Evolution of self-compatibility and racial differentiation in Leavenworthia (Cruciferae). Contr. Gray Herb., 195, 3-195.

LORD, E. M. AND HILL, 3. P. 1987. Evidence for heterochrony in the evolution of plant form. In: Raff, R. A. and Raff, E. C. (eds) Development as an Evolutionary Process, pp. 47-70. Alan R. Liss, New York.

MACNAIR, M. R. 1989. A new species of Mimulus endemic to copper mines in California. Bot. J. Linn. Soc., 100, 1-14.

MACNAIR, M. R. AND CUMBES, Q. J. 1989. The genetic architecture of interspecific variation in Mimulus. Genetics, 122, 211-222.

MARShALL, D. F. AND ABBotT, R. J. 1982. Polymorphism for outcrossing frequency at the ray floret locus in Senecio vulgaris L. I. Evidence. Heredity, 48, 227-235.

MARShall, D. F. AND ABBOTT, R. J. 1984. Polymorphism for outcrossing frequency at the ray floret locus in Senecio vulgaris L. II. Confirmation. Heredity, 52, 331-336.

MATHER, K. AND JiNKS, J. L. 1982. Biometrical Genetics, 3rd edn. Chapman and Hall, London.

MOORE, D. M. AND LEWIS, H. 1965. The evolution of self-pollination in Clarkia xantiana. Evolution, 19, 104-114.

ORNDUFF, R. 1969. Reproductive biology in relation to systematics. Taxon, 18, 121-133.

RICHARDS, J. H. AND BARRETT, S. C. H. 1992. The development of heterostyly. In: Barrett, S. C. H. (ed.) Evolution and Function of Heterostyly, pp. 85-127. Springer-Verlag, Berlin.
RITLAND, C. AND RITLAND, K. 1989. Variation of sex allocation among eight species of the Mimulus guttatus complex. Am. J. Bot., 76, 1731-1739.

RITLAND, K. 1991. A genetic approach to measuring pollen discounting in natural populations. Am. Nat., 138, 1049-1057.

Rollins, R. C. 1963. The evolution and systematics of Leavenworthia (Cruciferae). Contr. Gray Herb., 192, 3-198.

SAWHNEY, v. K. 1992. Floral mutants in tomato: development, physiology and evolutionary implications. Can. J. Bot., 70, 701-707.

SHORE, J. S. AND BARRETT, S. C. H. 1990. Quantitative genetics of floral characters in homostylous Turnera ulmifolia var. angustiflora Willd. (Turneraceae). Heredity, 64, 105-112.

SOLBRIG, O. T. AND ROLLINS, R. C. 1977. Breeding system and genetic variation in Leavenworthia. Evolution, 26, 155-160.

StebBins, G. L. 1950. Variation and Evolution in Plants. Columbia University Press, New York.

UYENOYAMA, M. K. AND WALLER, D. M. 1991a. Coevolution of self-fertilization and inbreeding depression. I. Mutationselection balance at one and two loci. Theor. Pop. Biol., 40, 14-46.

UYENOYAMA, M. K. AND WALLER, D. M. 1991b. Coevolution of self-fertilization and inbreeding depression. II. Symmetric overdominance in viability. Theor. Pop. Biol., 40, 46-77.

UYENOYAMA, M. K. AND WALleR, D. M. 1991c. Coevolution of self-fertilization and inbreeding depression. III. Homozygous lethal mutations at multiple loci. Theor. Pop. Biol., 40, 173-210.

VICKERY, R. K. 1978. Case studies in the evolution of species complexes in Mimulus. Evol. Biol., 11, 405-507.

WRight, s. 1968. Evolution and the Genetics of Populations, vol. 1. Genetic and Biometric Foundations. University of Chicago Press, Chicago.

WYATT, R. 1988. Phylogenetic aspects of the evolution of selfpollination. In: Gottlieb, L. D. and Jain, S. K. (eds) Plant Evolutionary Biology, pp. 109-131. Chapman and Hall, London.

ZENG, Z.-B., HOULE, D. AND COCKERHAM, C. C. 1990 . How informative is Wright's estimator of the number of genes affecting a quantitative character? Genetics, 126, 235-247. 